Respiration 2017;94:70

DOI: $10.1159 / 000473883$

\section{Pulmonary Vein Varices Are Syndromic Features in Turner Syndrome}

Mouhamad Nasser $^{\mathrm{a}} \quad$ Didier Revel $^{\mathrm{b}, \mathrm{c}}$ Hélène Thibault ${ }^{\mathrm{b}, \mathrm{d}}$ Chahéra Khouatra $^{a}$ Vincent Cottin ${ }^{a, c}$

a Department of Respiratory Medicine, National Reference Center for Rare Pulmonary Diseases, Hospices Civils de Lyon, ${ }^{b}$ Claude Bernard Lyon 1 University, University of Lyon, INRA, UMR754, and Departments of ${ }^{\mathrm{C}}$ Radiology and ${ }^{\mathrm{d}}$ Cardiology, Louis Pradel Hospital, Hospices Civils de Lyon, Lyon, France

We report herein a case of pulmonary vein varix in a 23 -yearold asymptomatic female patient with Turner syndrome (45, X), who was initially referred for transcatheter embolotherapy of suspected pulmonary arteriovenous malformations (PAVMs) found incidentally. Careful review of the computed tomography of the chest (Fig. 1) in fact did not show any pulmonary artery abnormality or aneurismal sac, ruling out PAVMs. The diagnosis of pulmonary varix associated with partial anomalous pulmonary venous return (PAPVR) was eventually established after thorough review of bizarre tortuous veins. Arterial blood gases were normal. Echocardiography did not demonstrate any other cardiovascular abnormality or pulmonary hypertension. Noninvasive follow-up was recommended.

Pulmonary vein varices are extremely rare, with fewer than 100 cases reported. They may be secondary to pulmonary venous hypertension caused by left heart disease [1] or to obstruction of pulmonary veins [2], or they may remain idiopathic, e.g., isolated or associated with other vascular malformations, such as PAPVR, coarctation of the aorta, or congenital heart disease.

Interestingly, we have previously reported in Respiration [3] a very similar case of pulmonary vein varix associated with PAPVR in a patient with Turner syndrome. At that time, the diagnosis of pulmonary varix was not raised until agitated saline echocardiography and $100 \%$ oxygen test failed to detect right-to-left shunt in the anomalous vessels spuriously suspected to correspond to PAVMs. Although such an association was considered possibly coincidental at that time despite a previous case [4], the current identical observation raises the hypothesis that the association of pulmonary varix with Turner syndrome may indeed represent a rare syndromic association related to genetic defects in vascular development.

\section{Financial Disclosure and Conflicts of Interest}

The authors declare that they have no conflicts of interest related to this article.
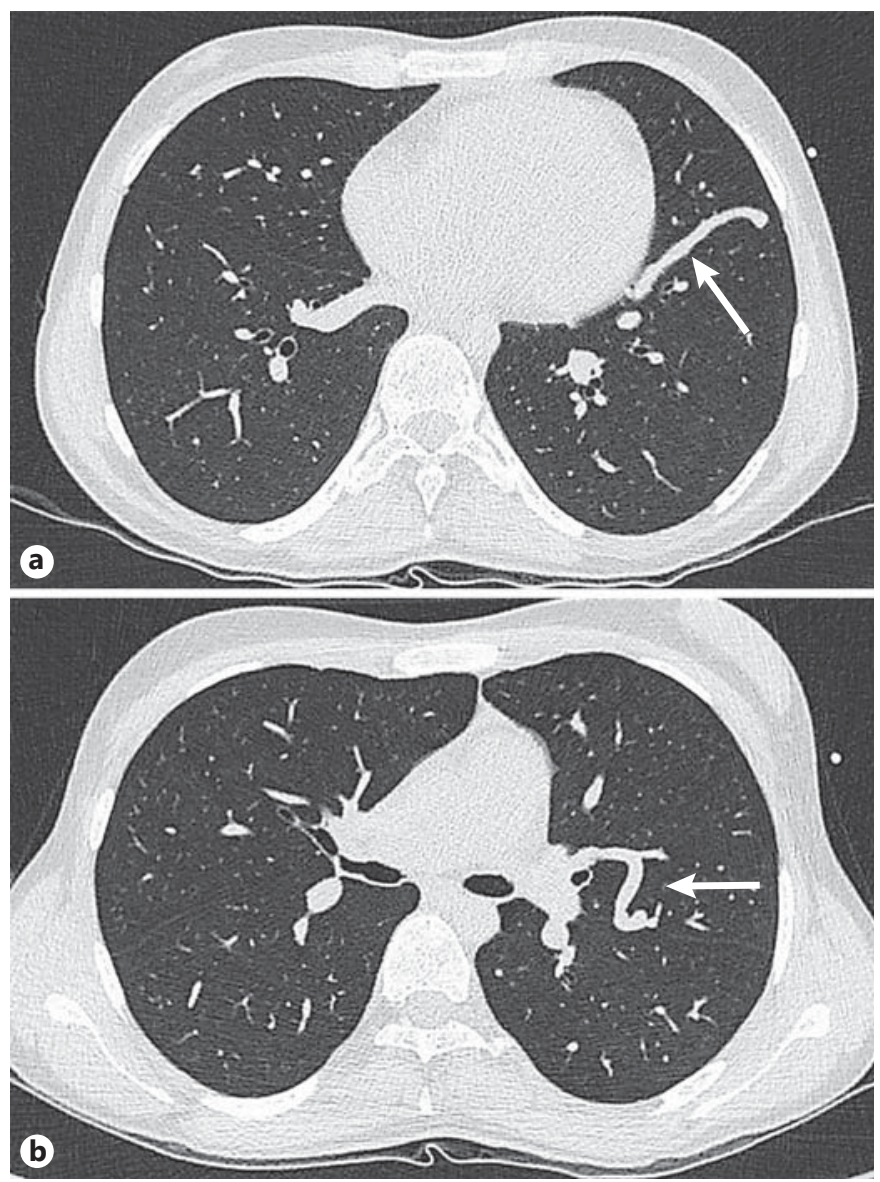

Fig. 1. Unenhanced computed tomography of the chest showing dilated pulmonary veins (pulmonary varices) in the lingula (a, arrow) and in the left upper lobe (b, arrow) crossing the fissure.

\section{References}

1 Iwasaki T, Amamiya K, Inaba S, et al: Reduction in pulmonary varix size after mitral valve replacement. J Cardiovasc Surg 1989;30:381-383.

2 Tajiri S, Koizumi J, Hara T, et al: A case of pulmonary varix associated with superior pulmonary vein occlusion. Ann Vasc Dis 2012;5:381-384.

3 Maillard JO, Cottin V, Mastroïanni BE, Frolet JM, Revel D, Cordier JF: Pulmonary varix mimicking pulmonary arteriovenous malformation in a patient with Turner syndrome. Respiration 2007;74:110-113.

4 Bartram O, Strickland B: Pulmonary varices. Proc R Soc Med 1971;64: 839.

\section{KARGER}

(C) 2017 S. Karger AG, Basel

E-Mail karger@karger.com

www.karger.com/res
Vincent Cottin

Service de Pneumologie

Bâtiment A4, 59 Boulevard Pinel

FR-69677 Lyon Cedex (France)

E-Mail vincent.cottin@ chu-lyon.fr 